\title{
0 "NÃO-PAPEL" FEMININO EM MANA MARIA
}

\author{
Monica Gomes da Silva \\ (UFRB) \\ https://orcid.org/0000-0002-9610-3017
}

\section{RESUMO}

O único romance escrito por António de Alcântara Machado d'Oliveira ${ }^{1}$, Mana Maria (1936), é apreciado, pelos principais intérpretes da obra machadiana, como o momento de consolidação do estilo praticado pelo prosador modernista. Destarte, o presente artigo propõe analisar a singularidade da obra na produção do escritor, partindo da revisão das duas principais vertentes da tradição crítica do romance. Em um primeiro momento, entende-se que Mana Maria constitui um avanço em relação ao tratamento da personagem, representando a saída da tipificação notada nas obras da década de 1920. Em um segundo momento, o romance passa a representar a defesa de valores dos "paulistas de 400 anos", um retrato de uma oligarquia em franca decadência social, dividida entre a glorificação do passado e a banalização do presente. O romance simbolizaria, ainda, a resposta amargurada de São Paulo à reação do país durante a Revolução Constitucionalista (1932). Para o estudo da tradição crítica e da questão da personagem no romance de 30, recorreu-se às análises de Mário de Andrade (1936), Luís Toledo Machado (1970), Cecília de Lara (1988), Sérgio Miceli (2001) e Luís Bueno (2015), entre outros. A partir do embasamento teórico proposto, demonstra-se a guinada no direcionamento literário de A. de A. M. com a elaboração do romance. Constata-se, assim, que o papel feminino adquire um novo status dentro da obra do artista, ao mesmo tempo que compartilha pontos de contato com as fortes representações femininas que povoam os romances de 30 .

PALAVRAS-CHAVE: romance de 30; Mana Maria; personagem feminina.

1 Neste artigo, preservamos a grafia original do nome do jornalista. Doravante, para nos referirmos ao escritor, usaremos as iniciais A. de A. M., a forma mais frequente com a qual assinava suas crônicas. Evitamos um dos problemas que incomodava ao jornalista e que ensejou algumas atribuições equivocadas em sua bibliografia: "Alcântara Machado é meu Pai. Eu sou António de A. M. No sumário figura meu Pai e não eu” (MACHADO, 1997, p. 49). 


\section{THE FEMALE “NON-ROLE” IN MANA MARIA}

\section{ABSTRACT}

The only novel written by António de Alcântara Machado d'Oliveira, Mana Maria (1936), is considered by the main commentators of his works as the consolidation of his modernist prose style. Thus, this article aims to analyze the singularity of this work in the author's production, based on the revision of the two trends of the novel critical tradition. Firstly, it is assumed that Mana Maria represents a step ahead when it comes to character construction, refusing the typification found in the works of the 1920's. Secondly, the novel starts to represent the defense of the " $400^{\text {th }}$ anniversary paulistas", a portrait of a socially decaying oligarchy, divided between the glorification of the past and the trivialization of the present. The novel allegedly also symbolizes São Paulo's bitter response to Brazil's reaction during the Constitutionalist Revolution (1932). In order to look into the critical tradition and the issue of character construction in the 1930's novels, the analyses by Mário de Andrade (1936), Luís Toledo Machado (1970), Cecília de Lara (1988), Sérgio Miceli (2001) and Luís Bueno (2015), among others, were helpful. On the basis of the theoretical background proposed, it becomes evident that this novel represents a turning point in A. de A. M.'s career. Thus, one can note that the female role acquires a new status within the author's work, whilst intersecting with powerful female representations that permeate the 1930's novels. KEYWORDS: 1930's novels; Mana Maria; female character.

\section{Introdução}

Dentre a variada produção do escritor paulistano A. de A. M. (19011935), o seu único romance, de publicação póstuma, possui destaque significativo no conjunto da obra do autor modernista. Mana Maria (1936) surge, na fortuna crítica machadiana, como a superação dos "cacoetes modernistas" (BARBOSA, 1988, p. 49). A obra representa o amadurecimento dos recursos narrativos inovadores e da inventiva linguagem literária pertencentes às crônicas e aos contos publicados pelo autor na década de 1920: 
a novela dita inacabada - Mana Maria, quanto à estrutura é completa. Não se pode tentar prever o que teria acontecido se a morte não interrompesse repentinamente sua trajetória. Mas, sem dúvida o escritor atingia sua maturidade expressiva e estava plenamente instrumentado para dar continuidade a sua produção (LARA, 1988, p. 72).

Se recordarmos que a trajetória do prosador priorizou as narrativas breves, a nova experimentação de A. de A. M. com o romance expressa tanto o já citado aprofundamento dos seus recursos narrativos aludidos por Barbosa e Lara, como também a inserção em um gênero de maior calado no cenário cultural. Embora a literatura brasileira tenha como a sua vertente mais pulsante e inovadora as narrativas curtas (CANDIDO, 2011, p. 254), conforme se observa nas décadas subsequentes à produção do escritor, a década de 1930 é reconhecida pela "ampliação e consolidação do romance" (idem, p. 246). Compreende-se, por conseguinte, o peso dado ao único romance elaborado por A. de A. M., ao pensarmos na importância assumida pelo gênero literário, cuja inovação ajudava a construir "uma nova maneira de escrever" (CANDIDO, 2011, p. 248) e alcançava grande sucesso de crítica e de público.

Desse modo, o artigo em tela busca estudar a singularidade do romance Mana Maria dentro da produção de A. de A. M., considerando as avaliações realizadas no sentido de coroá-lo como o ponto máximo de sua carreira. Apresentamos, como hipótese de trabalho, que tal característica distintiva se dá, também, através do tratamento temático da personagem feminina, para além da questão do gênero literário romance.

A personagem principal, Mana Maria, possui um protagonismo problemático, diferenciando-se da galeria limitada presente nas obras machadianas da década de 1920, porém já apresentando pontos de contato com as novas representações da figura feminina na década de 1930. O romance gira em torno da história de Maria H. Pereira que, após a morte da mãe Purezinha, assume o pleno controle da situação familiar comandando, rigidamente, as decisões financeiras e educacionais da irmã menor, Ana Teresa. Mana Maria, título conferido pela caçula, é austera, pragmática e independente, de um modo assustador para o pai Joaquim Pereira. A personagem, proibida de trabalhar como professora e limitada ao ambiente doméstico, vê o destino inexorável de mulher solteira ser contrariado com um pedido "atrevido" de casamento feito pelo médico sergipano Samuel Pinto. Após algumas idas e vindas, através das recordações das rejeições amorosas do passado e de um pequeno conluio familiar 
favorável ao pedido, a protagonista, de modo resoluto, recusa o papel de esposa, referendado socialmente. Mana Maria, apesar do estigma que acompanha essa recusa, assume as consequências do "não-papel", isto é, o de permanecer solteira, uma das formas da "marginalidade feminina" (BUENO, 2015, p. 324) abordadas no romance de 30.

Em nosso itinerário de análise de Mana Maria, na primeira seção, passamos pelas duas principais vertentes da tradição crítica da obra, bem como pela leitura a respeito do gênero romance e dos romancistas de 1930. Na segunda seção, realizamos uma comparação dentro do conjunto da obra de A. de A. M., ressaltando as mutações sofridas pela figura feminina em Mana Maria. Ao fim tecemos algumas considerações acerca desse protagonismo problemático através do não-papel feminino, uma tentativa de vislumbrar esse "outro" no romance de 30.

\section{Mana Maria: saída da tipificação, romance de "resistência paulista" e "crônica da casa assassinada"}

Ao cotejar a tradição crítica de Mana Maria, percebemos duas vertentes principais na interpretação do romance. A primeira, iniciada logo após o lançamento da obra, se detém na construção psicológica da personagem principal, que constituiria a diferença marcante dessa obra dentro da produção do escritor. O romance é entendido como o mergulho em uma subjetividade revelada tanto em seus aspectos externos, por meio da relação com os demais personagens e seu entorno social, quanto na imersão nos pensamentos e devaneios de sua protagonista. A segunda vertente, iniciada, aproximadamente, em 1959, explora os aspectos regionalistas e históricos da obra, destacando seu paulistismo ${ }^{2}$.

É bem representativo, da primeira vertente, o depoimento "O túmulo na neblina", de Mário de Andrade (1893-1945), publicado na coletânea Em memória de Antônio de Alcântara Machado (1936). Mário de Andrade comenta a mudança na produção do prosador: "E achado este conceito psicológico de herói, a curteza formal do conto já não interessava mais, seria quando muito um divertimento, desfatigar-se [sic] para o romancista nato. António de Alcântara Machado só pensava em romances" (ANDRADE, 1936, p. 106).

2 Termo utilizado para aludir à questão do caráter paulista, sendo recorrente nos textos dos autores modernistas, refletindo, assim, uma marca cultural do momento da obra. 
"Pensar em romances" assume o cunho de rito de passagem para uma literatura de estrutura mais elaborada, oposta à "curteza formal do conto", visto como texto para distrair da lide árida do romance. Revelam-se, pelo depoimento marioandradino, os parâmetros de legitimação em relação aos gêneros literários na década de 1930. Mário de Andrade é o comentador de primeira hora a apontar o tom mais grave da narrativa, bem como o maior desenvolvimento da vida interior da personagem, distinto dos flashes cômicos dos contos. A boutade e a derrisão caricatural dos contos de Brás, Bexiga e Barra Funda e Laranja da China se opõem à desolação do romance, permeado de humor mais sutil, comedido e com uma leve ponta de melancolia.

O memorialista estabelece um panorama da obra de A. de A. M., em que a leveza dos tipos e o olhar distante do narrador, por vezes zombeteiro ou sarcástico nas primeiras obras, são contrapostos a uma personagem com maiores nuanças, uma vida interior mais rica e intricada, somada a uma maior empatia do narrador. A caricatura dos contos cede espaço ao retrato do romance, e o escritor, livre do resguardar-se irônico diante da vida, se envolve, finalmente, na matéria narrada:

Resta Mana Maria porém. "Mana Maria vai indo. Tem sofrido tanto, coitada", ele me escrevia na última carta. António estava se transformando bem com a maturidade. À medida que o sósia se diluía, menos frequentemente alugado, como uma experiência mais dolorosa que satisfatória, em que o triunfo sobre o alheio não o consolava da impermanência do seu próprio ser, ele talvez chegasse a amar Mana Maria. À medida que se tornava cada vez menos lembrado de se utilizar do sósia, ia fazendo a mana criar pacientemente o sósia dela, o manequim que a devia substituir em tudo quanto ela considerava irresoluções da sua personalidade. Mas já agora o António sabia de sua própria experiência, ser o esforço de Mana Maria uma tentativa sem consolo: "Tem sofrido tanto, coitada." A frase queima, ante a superioridade fria com que António de Alcântara Machado contemplou sempre a aventura dos seres, levando todas as coisas percebidas a objeto do seu espírito. Não se guardava mais. Mana Maria era também afinal um objeto do seu coração (ANDRADE, 1936, p. 107-108).

Uma retomada e um aprofundamento dos comentários feitos por Mário de Andrade, no que concerne à questão do adensamento da personagem em Mana Maria, são realizados por Valdevino Soares de Oliveira (1980). Assim como no texto de Mário, o estudo demonstra a organização da narrativa em torno do tratamento da personagem e ratifica a linha de 
continuidade existente entre os gêneros de menor extensão e o romance. Além disso, assinala-se a consolidação de recursos narrativos que tornariam o texto de Mana Maria mais "comedido". Oliveira defende, entretanto, que o romance é o prosseguimento da tipificação do personagem, contrariando a hipótese de Mário de Andrade sobre a existência de uma análise psicológica mais densa:

Penso que não dá pra imaginar Alcântara Machado desfechando este romance de outra forma, pois, se nas outras obras o final é sempre vago, porque pode ser ponto de partida, isto é, começo para outros episódios, aqui isso ocorre. É uma narrativa que fica no ar, aberta para novas situações, numa sequência mais longa. Nos textos de Alcântara Machado, não há necessidade de ligar as pontas, retomando fatos passados. Os fatos são fatos e existem com vida própria. Encadeá-los é função do romancista, de acordo com a sua linha estética de construção. Neste autor surge como opção o final aberto. Portanto, Mana Maria é obra completa e acabada (OLIVEIRA, 1980, p. 113).

Nessa perspectiva, a personagem é um tipo, já que não se modifica ao longo da narrativa. Seus conflitos e embates com os demais não produzem mudanças substanciais em sua conduta:

Mana Maria é um romance cujos eventos só servem para delinear e caracterizar a personagem em sua pertinácia de mulher forte e controladora da situação. E a construção da personagem é uma das marcas da composição na narrativa de Alcântara Machado (idem, p. 113).

A segunda linha de leitura da obra, cujo expoente é Francisco de Assis Barbosa (1914-1991), destaca sua proximidade com os romances regionalistas de 1930. O debate em torno da personagem, sobre se porventura existe ou não uma crescente complexidade no seu desenvolvimento, sai do centro das discussões e ganha relevo a questão do romance como representação histórica.

O jornalista comenta o traço regional dos textos de A. de A. M., que inspira o título de Novelas Paulistanas, livro que reúne, pela primeira vez, todas as narrativas do escritor. O regionalismo da obra do modernista faz com que a obra seja associada aos grandes ciclos romanescos que representavam e valorizavam as características culturais de cada região do país:

Regionalismo que é a integração do homem no seu meio, com a sua gente, bichos e árvores; com a tradição, os costumes e as aspirações sociais; com as superstições, a religião, os sentimentos populares. Regionalismo, notadamente no "Ciclo da Cana-de-Açúcar", panorama de 
toda uma região e de toda uma época, do banguê à usina, ou seja, o esplendor e a decadência dos senhores de engenho. No "gauchismo" de Érico Veríssimo d'O Tempo e o Vento, o primeiro grande romance histórico da nossa literatura. No "mineirismo" de João Guimarães Rosa e Mário Palmério. No "paulistanismo" de António de Alcântara Machado. Regionalismo que é, em suma, mais do que uma afirmação nacionalista, porque, atinge o universal (BARBOSA, 1988, p. 52).

Francisco de Assis Barbosa recobra o impulso atribuído ao Modernismo que tomaria para si uma espécie de levantamento literário das diferentes regiões brasileiras, cuja pesquisa da brasilidade teria o seu ponto culminante na série romanesca de 1930. A partir dos tipos ítalo-paulistas e da experiência linguística, que por "sua procura da expressão brasileira da língua portuguesa" (idem, p. 49) é comparada ao projeto literário de João Guimarães Rosa, A. de A. M. logra representar tipos humanos universais, com seus dramas eternos e idênticos, apesar do flagrante da metrópole em expansão.

Podemos identificar uma continuidade dessa linha consolidada por Assis Barbosa no trabalho de Luís Toledo Machado (1970). Destacando o paulistismo na obra de A. de A. M., o romance Mana Maria é considerado, principalmente, através da associação com aspectos políticos marcantes do Estado de São Paulo na década de 1930. Mais precisamente, 1932, quando ocorre a Revolução Constitucionalista, que conduziu a uma guerra civil entre o Estado e os demais integrantes da República. Opondo-se à continuidade do governo provisório, empossado após a Revolução de Outubro de 1930, os dirigentes paulistas exigem a abertura de uma Assembleia Constituinte e novas eleições.

Entretanto, as forças que haviam ajudado a fomentar o movimento constitucionalista, os dirigentes mineiros e gaúchos, não auxiliaram as tropas paulistas quando o front de batalha se tornou real. São Paulo entra em guerra contra o governo de Getúlio Vargas. O isolamento do Estado em suas reivindicações é sentido como uma traição dos antigos aliados. A Revolução é debelada após conflitos que dizimaram parte da população civil.

Toledo analisa a trajetória da personagem Mana Maria como a elaboração dos conflitos políticos do Estado de São Paulo; especialmente, o sentimento separatista em relação ao restante do Brasil, sendo considerado um "romance de resistência paulista". A personagem é a expressão da essência da paulistanidade e a insurgência contra aqueles que atentam para a sua identidade: 
O romance abarca simultaneamente os dois grandes movimentos gerais da temática social paulista: o estreito mundo crepuscular da pequena classe média tradicional e "ufanista", esboçado na linha descendente da família de Mana Maria, e a mobilidade ascendente, de caráter sócio-geográfico, do imigrante interno, simbolizada pelo Dr. Samuel Pinto, médico sergipano. Mas o assunto central é deliberadamente o da insubmissão ao recém-chegado, ao vitorioso da Revolução de 32 , o que confere à obra o tom patético de romance de resistência paulista (MACHADO, 1970, p. 84).

Os traços da personagem — rigidez, energia e seriedade — seriam a projeção de características dos paulistas legítimos, de "400 anos”. Mana Maria encarna o papel substituto da matriarca que tenta salvaguardar uma tradição em ruínas devido à inépcia dos familiares do sexo masculino diante de uma nova cidade, sacudida pelo crescimento e pela mescla cada vez maiores. Ao fim do estudo, Toledo retoma as considerações marioandradinas sobre a questão do personagem em A. de A. M.

Por mais interessante que seja a vinculação com o contexto histórico, existem traços da personagem que escapam ao escopo do "romance de resistência paulista". Mana Maria, como um símbolo da Revolução Constitucionalista, apresenta um perfil forte e dominador, cioso dos valores morais a serem defendidos da "invasão" das outras partes do país numa cidade com grande efervescência cultural e política.

Contudo, o final problematiza essa aparente "inteireza" moral, representativa dos valores paulistanos, que constituiriam, para a crítica de Toledo, um dos tipos fixos de A. de A. M. Ainda que o crítico associe a decisão final da personagem ao orgulho paulista, os sentimentos experimentados e a resolução pela absoluta solidão não são sentidos como uma vitória. É perceptível, nas reflexões da personagem, uma consciência trágica do destino escolhido, cuja leitura possibilita transcender a questão da orgulhosa derrota paulistana durante a Revolução Constitucionalista.

Por outro lado, outra vinculação interessante, dentro da linha de representação histórica, é aquela do romance de A. de A. M. ao que Sérgio Miceli denomina de "cronistas da casa assassinada". O sociólogo destaca a nova função assumida pelo romance de "interpretação de um mundo social", que havia passado, antes, pelos manifestos e poemas modernistas na década de 1920. A respeito dessa virada e do predomínio, pela primeira vez, do romance na literatura brasileira, transcrevemos a análise de Miceli. Conquanto seja um pouco extensa, consegue captar aspectos importantes da mudança supracitada: 
Embora o alvo preferido dos ataques modernistas fosse o tipo de poesia praticado pelos parnasianos, decadentistas e outros círculos simbolistas, os escritores modernistas de São Paulo e Minas nunca conseguiram se desvencilhar por completo das normas intelectuais vigentes na década de 1920, segundo as quais a poesia era tida como o gênero social mais rentável.

Não é de estranhar, portanto, que a "carreira" de romancista tenha se configurado em sua plenitude apenas na década de 1930, num momento em que o desenvolvimento do mercado do livro se alicerçava na literatura de ficção, então o gênero de maior aceitação e de comercialização mais segura. [...]

Num período de intensa concorrência ideológica e intelectual entre diversas organizações políticas (integralismo, Igreja, forças de esquerda), o romance converteu-se em móvel importante de luta em torno da imposição de uma interpretação do mundo social a um público emergente: os grupos de esquerda classificavam as obras dos romancistas identificados com a Igreja de romances "introspectivos" ou "psicológicos", os críticos de direita ou de tendências espiritualistas rotulavam as obras dos militantes de esquerda de romances políticos em sentido pejorativo, ou seja, como obras de propaganda e proselitismo (MICELI, 2001, p. 159, grifo nosso).

O fim da utopia modernista coincide com a ascensão dos novos escritores que se voltam para o declínio das grandes forças tradicionais que entraram em colapso. A bancarrota financeira das oligarquias foi um dos motores da Revolução de 1930. Os romances possuem personagens cujas trajetórias individuais representam o conflito diante de uma estrutura social em convulsão, decorrente da mudança histórica da passagem de um mundo rural a um mundo urbano. Sem entrarmos na discussão do sociólogo, de que a obra dos "cronistas da "casa assassinada" significa, na verdade, "uma transposição literária de sua experiência pessoal" (idem, p. 161), o fato é que existe uma tentativa de reinterpretação da realidade brasileira. No entanto, a "redescoberta" do país se dá em termos de aporia e desencanto. Para o impasse vivido, tirantes aqueles filiados, nitidamente, a alguma concepção ideológica, os romances deixam a resposta em aberto.

Mana Maria estaria bem próximo da crítica que permeia essa linha de romances formulada por Miceli. No caso da obra de A. de A. M., percebemos, ademais, uma mudança de perspectiva similar ao trajeto dos "cronistas" estudados por Miceli: o discurso utópico diante da moderni- 
zação, nos contos da década de 1920, é substituído pelo desencanto diante do "problema Brasil", como era comum aos romances da década de 1930.

Portanto, ao contrário do que se afirmou na segunda vertente de interpretação da obra, não há uma defesa do "paulista de 400 anos". O romance, ainda preservando o traço caricatural da primeira fase da obra machadiana, ridiculariza a prosápia de classe, o amor às genealogias e cargos, desvelando as ações espúrias de uma classe com virtudes de fachada. Assim como os "cronistas da casa assassinada", A. de A. M. aponta os problemas de uma tradição corrompida e decrépita. Mana Maria é a mulher que tenta sobreviver ao embate entre uma moral e um estilo de vida já condenados e a ascensão dos novos atores e formas de sociabilidade. O caminho desolador adotado coincide com os finais solitários e/ ou trágicos dos romances de 30 apontados por Miceli.

O levantamento realizado revisa as diversas linhas de interpretação para a singularidade do romance de A. de A. M., seja pelo trabalho inédito de construção da personagem, seja pelas questões sócio-históricas do romance na década de 1930. Passamos à nossa proposta para a análise da particularidade da obra em comparação com os demais textos do prosador modernista. Nesse sentido, aventamos a hipótese de que Mana Maria possua uma diferença substancial dentro da produção do escritor em relação às personagens femininas, em sintonia com as novas representações realizadas pelo romance de 30 .

\section{A (im)possibilidade de uma terceira via: o "não- -papel” feminino em Mana Maria}

Nas primeiras crônicas publicadas por A. de A. M., no início da década de 1920, a galeria das personagens femininas é composta pelas estrelas do cinema e do teatro, misteriosas, admiradas e desejadas; a "andrógina furiosamente moderna", as moças que aderiam às novas modas e hábitos, como usar cabelos curtos e fumar, sendo classificadas como volúveis; ou as "ardentes defensoras das reivindicações feministas", isto é, as feministas e suas pautas "risíveis". A mulher ou é a musa cortejada e desejada, ou a ameaça que extrapola os papéis que lhe foram designados. Em algumas crônicas, as conquistas femininas são ridicularizadas e se teme uma assunção de funções até então masculinas. Em crônica de outubro de 1924, é bem gritante o incômodo diante das conquistas obtidas pelas mulheres que implicariam, necessariamente, na perda da feminilidade: 
Nesta época de mulheres de cartola, cabelos aparados, vestes masculinas; mulheres eleitoras, operárias, políticas, legisladoras; mulheres que querem a toda força ter os mesmos direitos e as mesmas vantagens dos homens, é justo, é justíssimo, que seja obrigatório para elas também o serviço militar...

Já que para o sexo de saias se abrem, acolhedores e fáceis, os congressos legislativos, as escolas superiores, os pretórios, as repartições públicas, os ministérios, tudo quanto era até agora o privilégio dos homens, é lógico que se lhes abra também a caserna com todas as suas comodidades e seduções... (MACHADO, 1983, p. 114).

Em crônica de julho de 1926, aparece a discordância para com a necessidade de uma política pública voltada para as mulheres. Para o cronista, ainda que reivindiquem direitos, as mulheres possuem "horror às responsabilidades". Desse modo, as mulheres reunidas em uma associação em prol do voto feminino consideraram "mais prudente conservar as coisas como estão" (idem, p. 151). Na crônica, reclama da falta de necessidade dum Ministério da Mulher:

Todas as questões femininas apontadas podem ser e estão sendo resolvidas sem o tal Ministério. Em toda a parte, há nos aparelhos administrativos repartições que se ocupam de todas elas. Em matéria de legislação de trabalho e de higiene até hoje não houve necessidade de distinguir $\operatorname{sexos...~[...]~}$

Enfim as mulheres desejam ser protegidas. Mas desejam de tal maneira que a gente tem a impressão de que o Ministério sugerido será uma espécie de Sociedade Protetora dos Animais...

E o pior é que a ideia brotou do cérebro de um marmanjo! (idem, p. 151-152).

Fica marcado, nos anos iniciais de sua produção, o desconforto perante os novos papéis encampados pelas mulheres. Quando passamos ao campo da ficção, nos contos, a representação da mulher moderna também não recebe um tratamento distinto. Se no espaço das crônicas a mulher independente não figura muito bem, no espaço ficcional, ela simplesmente não aparece. A galeria se restringe às mães e às moças solteiras, cujos interesses se voltam para os casos amorosos.

As matriarcas são as responsáveis pelo núcleo organizador da família. Existem as abnegadas, como a "Insigne Cornélia" de Laranja da 
China (1928), que se desdobram para atender a todas as exigências da família, cansando-se e se anulando em uma estafante rotina diária. As mães proletárias também aparecem em uma dura realidade de cuidados entre o trabalho e uma prole numerosa. Embora algumas possuam voz dentro das decisões familiares e resolvam os problemas causados pela falta de habilidade dos homens, como a Silvana de "O ingênuo Dagoberto", também de Laranja da China, o valor dessas personagens se concentra na capacidade de suster a família.

Na galeria das moças solteiras, as jovens são o alvo de um julgamento mais severo. As mulheres retratadas dividem-se em duas categorias. A primeira é a da mocinha voluntariosa, recordando os famigerados estereótipos das "Marias" (Maria-gasolina, Maria-chuteira), ou seja, as mulheres interesseiras e que usam os atrativos físicos para conseguir vantagens. Aqui são retratadas as adolescentes imaturas que desejam/imaginam viver aventuras amorosas. Elas adotam hábitos modernos, vão a bailes, usam cabelos curtos, trajam "vestidos futuristas" e estão a par dos avanços tecnológicos que expressam as novas sociabilidades: o rádio, o cinema e o telefone. Entram, nessa categoria, a "Apaixonada Elena" e a Silvana de "O ingênuo Dagoberto", ambas de Laranja da China.

$\mathrm{Na}$ segunda categoria, as moças, algumas das quais são operárias, também apresentam a adesão aos novos hábitos e, apesar de sonharem com príncipes e aventuras românticas, não são tão ingênuas quanto as moças da primeira galeria, e utilizam a beleza para obterem pequenos prazeres. Assim é a Carmela de Brás, Bexiga e Barra Funda (1927), "costureirinha" que desperta o desejo dos homens e, de forma prática, divide os homens em "namorado para casar" e namorado para passear pela cidade a bordo de um automóvel. Contudo, secretamente, possui sonhos amorosos que reserva para si, alimentados pelos folhetins romanescos e fitas de cinema, numa dicotomia que recorda bastante a vivida pela Fräulein Elza do romance de Mário de Andrade, Amar, verbo intransitivo (1927). Também em Brás, Bexiga e Barra Funda, a personagem Miquelina não hesita em abandonar o namorado, jogador de futebol perdedor, pelo jogador vitorioso do campeonato. Nos dois casos, é a novidade que impressiona e modula o desejo dessas mulheres. O status conferido pelo automóvel, um símbolo de poder e distinção, e o destaque crescente do futebol como identidade e força econômica, são discutidos na obra de A. de A. M.

Cabe, ainda, o destaque à questão da violência contra a mulher, mostrando que a independência incipiente não era uma conquista aceita 
facilmente. Nicolino, personagem principal do conto "Amor e Sangue" de Brás, Bexiga e Barra Funda, assassina a ex-namorada que se recusa a reatar o relacionamento. Em "O tímido José", de Laranja da China, a representação é mais densa. José persegue uma moça pelas ruas paulistanas, madrugada adentro, imaginando tratar-se do "tipo disponível" para aventuras. A interpretação equivocada dos sinais dados pela moça é reforçada pela lembrança dos conselhos do amigo machista sobre o que "realmente desejam" as mulheres. O desfecho do suspense, i.e., se o personagem vai concretizar ou não a aventura com a mulher perseguida, é brutal. Essa, ao chegar em casa, é recebida por agressões verbais e físicas por um suposto marido. Embora a violência permeie o conto, o personagem fica atônito quando o comportamento cruel acontece.

As personagens revisitadas até aqui, tanto nas crônicas, quanto nos contos, revelam uma visão tradicional acerca do papel feminino. $\mathrm{O}$ autor critica as demandas feministas, enaltece a figura materna e desenha um lado ridículo para as moças casadoiras, fascinadas pela moda e os novos hábitos. Nesse sentido, os tipos se aproximam da velha tríade romântica: a santa, a mulher fatal e a prostituta. As transformações sociais já quebram esses paradigmas, o que faz com que o esquema não possa ser aplicado integralmente. Não se detendo sobre o aspecto da prostituição, bem velado nos primeiros textos, ficam a mulher fatal e a mulher santa. Em relação a essas imagens femininas, polarizadas entre a "virtude" e a "perdição", aparece a representação das moças solteiras que escapam a esse enquadramento, ainda assim, sob um forte traço caricatural, sendo apresentadas como interessadas/interesseiras pela moda e por casos amorosos. Uma terceira via para o papel destinado à mulher na sociedade brasileira estava em construção e, através dos textos machadianos, ouve-se o coro de vozes que repudiam e ridicularizam, veementemente, as "feministas/futuristas" que escapam à tutela masculina.

Entretanto, o esquematismo da representação feminina não é exclusividade da obra de A. de A. M. e, na década de 1930, é patente o confronto desses estereótipos com as novas realidades sócio-culturais do cenário brasileiro em mutação. Recordamos, aqui, o estudo de Luís Bueno (2015) sobre o romance de 30, pensando no momento da escrita da obra (1935), precisamente, em "plena polarização" (BUENO, 2015, p. 159) política/ estética que reponta nos romances do período. Para além das dicotomias analisadas por Bueno - esquerda X direita, Norte X Sul, romance proletário X romance intimista - interessa-nos a questão das vozes que se 
fazem ouvir, mais fortemente, no romance brasileiro daquele momento e o problema, para o escritor, na representação da alteridade:

Junto com os "proletários", outros marginalizados entrariam pela porta da frente na ficção brasileira: a criança nos contos de Marques Rebelo; o adolescente, em Octávio de Faria; o homossexual, em Mundos Mortos do próprio Octávio de Faria e no Moleque Ricardo, de José Lins do Rego; o desequilibrado mental em Lúcio Cardoso e Cornélio Penna; a mulher, nos romances de Lúcia Miguel Pereira, Rachel de Queiroz, Cornélio Penna e Lúcio Cardoso.

Uma abertura desse tipo coloca para o intelectual, oriundo geralmente das classes médias ou de algum tipo de elite decaída, o problema de lidar com um outro. Esse problema foi vivido em profundidade pelos autores daquela década e bem ou mal resolvido de várias maneiras diferentes (BUENO, 2015, p. 23).

Trabalhar com as margens estigmatizadas na sociedade brasileira, cujas representações eram sobrecarregadas de preconceitos e de exotismo, nas obras literárias até aquele momento, é um desafio para os autores que, lembrando muito a análise de Miceli, são "cronistas da 'casa assassinada"'. É através da tessitura do texto e da tentativa de preservação dessas vozes abafadas, elidindo as pretensas barreiras (linguísticas e de classe) entre narrador e personagem, que são produzidos os melhores momentos dessa literatura.

Em relação à representação da mulher no romance de 30, Luís Bueno nota um binômio recorrente: a mulher casada ou a prostituta. $\mathrm{O}$ casamento é o destino "certo" a ser seguido, seja nos romances de esquerda ou direita. A saída de casa e, por conseguinte, da tutela masculina, é um dos passos para a perdição. As atitudes de revolta são punidas com a decadência física e moral das personagens via prostituição: "Nunca se viu tanta mulher caindo na vida como no romance de 30" (BUENO, 2015, p. 302). Existe a dificuldade, como nos textos de A. de A. M. na década de 1920, de se conceber um outro papel para a mulher fora dessa dualidade. Avulta a questão autoral para se pensar este esquematismo:

É uma espécie de sintoma de que a ficção brasileira, assim como criara uma imagem simplificadora e exótica do homem do campo, do pobre, também aprisionara a mulher numa concepção redutora demais. De fato, é muito difícil encontrar textos escritos por homens que, colocando esse tipo de problema no centro temático de sua obra, pelo menos indiquem, como fez Arnaldo Tabayá, que os papéis de prostituta e de 
esposa não dão conta da figura feminina a essa altura do campeonato — se é que deram em alguma ocasião (BUENO, 2015, p. 302).

Luís Bueno atribui às escritoras, com destaque para Rachel de Queiroz e Lúcia Miguel-Pereira, a construção de uma terceira via: a mulher que opta, apesar das coerções familiares e sociais, por permanecer solteira. A escolha "condenável" problematiza a dicotomia anterior e demonstra os embates de mulheres que, de modo vacilante, sinalizam o desejo de um destino que não seja o matrimonial. Embora haja poucos escritores que consigam sair do binômio esposa X prostituta, a escolha "condenável" figura, também, em obras de autoria masculina, conforme aponta Bueno: Arnaldo Tabayá, Newton Sampaio, Cornélio Pena e Graciliano Ramos. Poucas, se pensarmos quantitativamente, mas fundamentais para sinalizar a "percepção de que havia a necessidade de descobrir ficcionalmente a mulher de uma maneira menos redutora" (BUENO, 2015, p. 302).

Todavia, curiosamente, no vasto painel elaborado pelo crítico, o único romance de A. de A. M. não é citado. Mana Maria é a análise da mulher que, entre hesitante e obstinada, decide permanecer solteira. A protagonista machadiana recorda, em parte, o perfil de uma das personagens do romance de Lúcia Miguel-Pereira analisada por Bueno:

Acaba se reduzindo à velha forma de marginalidade feminina. Não cumpre seu destino de esposa, mas também não cai no papel oposto, de prostituta. Só lhe sobra o não-papel de solteirona. [...] percebe que não deixaria traço nenhum de sua existência sobre a terra. Um ser que nada é, que se define por sua relação com os outros (BUENO, 2015, p. 324).

As complicações da trama são de ordem interior e a dicotomia, tão bem percebida por Mário de Andrade, é o contraponto que faz com que a tipificação da primeira galeria seja abandonada em prol de um mergulho subjetivo numa "criatura de transição" (BUENO, 2015, p. 332). Contudo, as "irresoluções" da Mana são um fervilhar de juízos, imagens, experiências e preconceitos dispersos nos demais personagens e no ambiente onde se move a protagonista, entrelaçando o fio social imprescindível do romance de 30 .

A relação dentro/fora reporta-se não só à oposição entre o estado de espírito indeciso e a aparência rígida e resoluta de Mana Maria, quanto também aos procedimentos de apresentação da personagem. Recobrando as inovações da prosa modernista de A. de A. M., pode-se pensar num movimento cinematográfico que, metonimicamente, num crescente clo- 
se-up, desvela o perfil dessa mulher. O momento inicial do romance é expressivo: a doença e a morte da matriarca da família, D. Purezinha, cujo nome no diminutivo contradiz o modelo feminino dominador dessa família. Mana Maria assume as tarefas de ordem financeira às quais o pai, Joaquim Pereira, não foi capaz de fazer frente. A partir do ângulo da pequena Ana Teresa, responsável pela alcunha que será levada como um título de autoridade pela irmã mais velha, inicia-se a construção do perfil de Maria H. Pereira. A "revelação física" já consegue, com poucos elementos, fixar a fachada austera e enérgica. Os óculos de aro de tartaruga são o remate que faltava ao conjunto: "Ficava completa" (MACHADO, 1988, p. 192).

Paulatinamente, vamos nos aproximando da personagem que tem como maior validação, por parte da família, o fato de seguir, tal e qual, o comportamento da mãe: "uma substituta, sua filha de palavra medida e dura, gesto brusco e decidido, olhar firme, direto, autoritário" (MACHADO, 1988, p. 198). Mana Maria passa a controlar os negócios familiares; resolve a partilha da herança materna em favor de Ana Teresa; envia a irmã para um colégio interno e proíbe que o pai compre um automóvel. As decisões incisivas são seguidas, sem contestação, pelo pai que "estourava de admiração: - Você é sua mãe escarradinha" (idem).

O controle excessivo da personagem se reflete na higiene "furiosa", no conhecimento e trato das questões financeiras, uma moralidade estrita, uma aparência sem ornatos, descontando os inquisidores óculos de aro de tartaruga. Essa ordem aparente é posta em perigo, ao surgir, pela primeira vez, a atenção de um pretendente. O interesse do Dr. Samuel Pinto, - acerca do sobrenome sugestivo do personagem, retomamos uma de suas falas: "Freud explica" (MACHADO, 1988, p. 237) — é suficiente para fazer emergir todo um passado de rejeição. A lembrança da dolorosa descoberta, na adolescência, de que "Era respeitada. Não era desejada" (MACHADO, 1988, p. 208), vai desfazendo a inteireza moral enxergada pelos demais personagens.

O segundo modelo feminino admirado por Mana Maria é a tia Carlota. Antítese do modelo materno de Mana, uma coquete, volátil e vaidosa, que atrai a sobrinha pelo seu desprendimento e sedução. Ela participará da trama para arranjar o pedido de casamento. Nesse ínterim, são recorrentes as falas sobre a necessidade de casamento, até pela moderna Carlota, e o destino "gorado" de uma mulher que não se casa, bem como o desamparo pela ausência de uma figura masculina. Ao mesmo tempo, acompanhamos uma espécie de bovarismo que, a muito custo reprimido, 
começa a vislumbrar um relacionamento amoroso do qual a personagem se acreditava excluída. Por fim, Mana decide manter a resolução em não se casar: "Tinha traçado uma linha de vida e dela nada a afastaria. [...] E lhe ficava como sempre a volúpia de pensar: - Eu poderia fazer assim, entretanto fiz assado que era o mais difícil. Não me traí. E se me sacrifiquei foi a mim mesma" (MACHADO, 1988, p. 210).

É significativo, mais ao fim do romance, o episódio do assédio sofrido no cinema, pois revolve as inquietações da opção celibatária: o desejo sexual não realizado. A fachada moral construída para lidar com a rejeição sofre suas fraturas e a libido que foi sendo recalcada, desde a adolescência, pulsa ao fim da narrativa. Fica patente a (im)possibilidade de uma terceira via, sem que haja perdas na "plenitude vital". A independência dessas mulheres é acompanhada de solidão, deixando "entrever que a alegria só seria possível depois de um longo caminho, ainda todo por trilhar" (BUENO, 2015, p. 332).

O filme a que assiste, a propósito, é indicativo dessa dubiedade: A mulher vendida, estrelado por Greta Garbo. Ainda que não exista, segundo nossa pesquisa, um filme exatamente com este título, o modelo da vamp, odiado por Mana Maria, é sugestivo daquilo de que a personagem abdica em favor de sua autonomia, em especial, a realização sexual. Por uma dessas coincidências fortuitas, a fala mais famosa de umas das personagens de Greta Gabo é: "I want to be alone" (Eu quero ficar sozinha). Ressoando de modo trágico, se pensarmos no fecho da narrativa machadiana, a frase corresponde à condição solitária no impulso de autonomia dessas figuras femininas, fora do binômio esposa-prostituta, expressão de uma vontade incompreendida e indesejada socialmente.

\section{REFERÊNCIAS BIBLIOGRÁFICAS}

ANDRADE, M. de et al. In: MACHADO, J. de A. (org.). Em memória de António de Alcântara Machado. São Paulo: Elvino Pocai, 1936.

BARBOSA, F. de A. Nota sobre António de Alcântara Machado. In: MACHADO, A. de A. Novelas paulistanas. 1. ed. rev. e ampl. Introd. C. de Lara. Rio de Janeiro: Itatiaia; São Paulo: Editora da Universidade de São Paulo: 1988, p. 27-52. 
BUENO, L. Uma história do romance de 30. 1. ed. 1. reimp. São Paulo: Editora da Universidade de São Paulo/ Campinas: Editora da Unicamp, 2015.

CANDIDO, A. A nova narrativa. In: . A educação pela noite. 6. ed. Rio de Janeiro: Ouro sobre Azul, 2011, p. 241-260.

LARA, C. de. Introdução. In: MACHADO, A. de A. Novelas paulistanas. 1. ed. rev. e ampl. Rio de Janeiro: Itatiaia; São Paulo: Editora da Universidade de São Paulo: 1988, p. 53-72.

MACHADO, L. T. Antônio de Alcântara Machado e o Modernismo. Rio de Janeiro: José Olympio, 1970.

MACHADO, A. de A. Novelas paulistanas. 1. ed. rev. e ampl. Introd. C. de Lara. Rio de Janeiro: Itatiaia; São Paulo: Editora da Universidade de São Paulo: 1988.

. Pressão afetiva \& aquecimento intelectual. Org. C. de Lara. São Paulo: Educ, 1997.

. Prosa Preparatória \& Cavaquinho e Saxofone. Org. C. de Lara. Vol. 1. Rio de Janeiro: Editora Civilização Brasileira, 1983.

MICELI, S. Intelectuais à brasileira. São Paulo: Companhia das Letras, 2001.

OLIVEIRA, V. S. de. A linguagem de Alcântara Machado: uma vertente modernista. Dissertação, FFLCH/USP, 1980.

Recebido em: 31/07/2019

Aceito em: 24/01/2020 